Original Article

\title{
Cigarette Smoking does not Induce Plasma or Pulmonary Oxidative Stress after Moderate-intensity Exercise
}

\author{
Shunsuke Taito, RPT, PhD'), Sayaka Domen, RPT, MS ${ }^{2)}$, Kiyokazu Sekikawa, RPT, PhD ${ }^{2)}$, \\ Norimichi Kamikawa, RPT, MS ${ }^{2)}$, Keisuke Oura, RPT ${ }^{2)}$, Tatsushi Kimura, PhD ${ }^{3)}$, \\ Makoto Takahashi, RPT, $\mathrm{PhD}^{2)}$, Hironobu Hamada, MD, $\left.\mathrm{PhD}^{2}\right)^{*}$ \\ 1) Department of Clinical Support, Hiroshima University Hospital, Japan
}

2) Department of Physical Analysis and Therapeutic Sciences, Graduate School of Biomedical and Health Sciences, Hiroshima University: 1-2-3 Kasumi, Minami-ku, Hiroshima 734-8553, Japan

3) Department of Kindergarten Education, Yasuda Women's College, Japan

\begin{abstract}
Purpose] Cigarette smoking increases oxidative stress, which is a risk factor for several diseases. Moreover, strenuous exercise has been shown to induce plasma and pulmonary oxidative stress in young cigarette smokers. However, no previous reports have demonstrated whether plasma and pulmonary oxidative stress occur after moderate-intensity exercise. Therefore, the aim of this study was to clarify whether moderate-intensity exercise induces pulmonary and plasma oxidative stress in smokers. [Subjects] Ten young male smokers and 10 young male nonsmokers participated in this study. [Methods] Plasma hydroperoxide concentrations were measured at baseline and then immediately and $15 \mathrm{~min}$ after moderate-intensity exercise. Hydrogen peroxide concentrations in exhaled breath condensate were measured at baseline and after exercise. [Results] No significant interactions were found between smokers and nonsmokers in terms of hydroperoxide or hydrogen peroxide concentrations following moderate-intensity exercise at any time point. [Conclusion] These findings suggested that moderate-intensity exercise did not induce plasma or pulmonary oxidative stress in young cigarette smokers.

Key words: Oxidative stress, Cigarette smoker, Moderate-intensity exercise
\end{abstract}

(This article was submitted Sep. 2, 2013, and was accepted Oct. 2, 2013)

\section{INTRODUCTION}

Oxidative stress is produced by reactive oxygen species (ROS) and is regulated by the expression and activity of antioxidants. Cigarette smoke is a complex mixture of thousands of chemical compounds, ROS, and other oxidants ${ }^{1)}$ and is associated with increased oxidative stress in the blood and lungs ${ }^{2,3)}$. Oxidative stress is one of the pathogenic mechanisms of several pulmonary and cardiovascular diseases $^{4-6)}$.

Exercise also induces oxidative stress. Strenuous exercise has been shown to induce plasma ROS generation in nonsmokers ${ }^{7-10)}$. Moreover, cigarette smoking increases the levels of plasma and pulmonary oxidative stress in concert with exercise. Interestingly, strenuous exercise produces higher amounts of ROS generation in the plasma and lungs of cigarette smokers than in those of nonsmokers ${ }^{11-13)}$.

Moderate-intensity exercise promotes health, rehabilitation, and improvement of physical fitness ${ }^{14)}$. Therefore, it

*Corresponding author. Hironobu Hamada (E-mail: hirohamada@hiroshima-u.ac.jp)

C2014 The Society of Physical Therapy Science. Published by IPEC Inc. This is an open-access article distributed under the terms of the Creative Commons Attribution Non-Commercial No Derivatives (by-ncnd) License $<$ http://creativecommons.org/licenses/by-nc-nd/3.0/>. is important to clarify whether plasma and pulmonary oxidative stress are induced by moderate-intensity exercise in smokers. However, no reports have investigated this topic. Thus, the aim of this study was to clarify whether smokers have increased plasma and pulmonary oxidative stress responses to moderate-intensity exercise compared with nonsmokers.

\section{SUBJECTS AND METHODS}

\section{Subjects}

The participants consisted of 10 male smokers and 10 male nonsmokers. All participants were untrained, did not participate in a regular exercise program, and were not regular cyclists. Participants were excluded from enrollment in the study if they had a history of metabolic, cardiovascular, or pulmonary disease or if they had orthopedic limitations. None of the participants were treated with antioxidant compounds (including vitamins) or anti-inflammatory medications. This protocol was approved by the Ethics Committee of the Hiroshima University Graduate School of Health Sciences (\#1047). Written informed consent was obtained from all subjects.

\section{Methods}

Subjects were instructed to abstain from strenuous phys- 
ical activity on the test day. Smokers refrained from smoking cigarettes for $12 \mathrm{~h}$ before the study to avoid the acute effects of cigarette smoking on hydroperoxide concentrations in plasma and hydrogen peroxide $\left(\mathrm{H}_{2} \mathrm{O}_{2}\right)$ concentrations in exhaled breath condensate $\left.(\mathrm{EBC})^{3}, 12,13\right)$.

Heart rate (HR) and oxygen consumption during cardiopulmonary exercise testing (CPX) using a cycle ergometer were measured by an electrocardiogram monitor with a telemetry system (Dynascope DS-3140, Fukuda Denshi, Tokyo, Japan) and a gas analysis system (AE-300; Minato Medical Science, Tokyo, Japan). The predicted $\mathrm{VO}_{2} \max$ was calculated by extrapolation of the heart rate and oxygen consumption at several submaximal workloads. The target HR during moderate-intensity exercise corresponded to that of $60 \%$ of the $\mathrm{VO}_{2}$ max. A week or more after CPX, subjects performed moderate-intensity exercise, which required pedaling at their target HR.

Blood samples were collected from subjects' fingertips using a single-use lancing device (ACCU-Chek Safe-T-Pro Plus; Roche, Mannheim, Germany) at baseline and then immediately and $15 \mathrm{~min}$ after exercising. Blood samples were centrifuged at $6,000 \mathrm{rpm}$ for $2 \mathrm{~min}$ using a centrifuge (2420; Kubota, Tokyo, Japan) and then frozen at $-30^{\circ} \mathrm{C}$ until analysis.

EBC samples were collected for $15 \mathrm{~min}$ at baseline and after moderate-intensity exercise using a dedicated breath refrigeration circuit (ECoScreen; Jaeger, Wurzburg, Germany $)^{12)}$. Participants wore a nose clip and a mask, and the mask was connected to a dedicated breath refrigeration circuit cooled to $-20^{\circ} \mathrm{C}$. The collected EBC samples were immediately used for measurement of $\mathrm{H}_{2} \mathrm{O}_{2}$ concentrations.

Plasma hydroperoxide concentrations were determined with a Diacron derivatives of reactive oxygen metabolites (d-ROMs) test kit (Grosseto, Italy) using a spectrophotometer (Free Radical Elective Evaluator; Diacron) ${ }^{13)}$. $\mathrm{H}_{2} \mathrm{O}_{2}$ concentrations were measured in EBC samples with a d-ROMs Exhalation Test Kit (Diacron) using a spectrophotometer ${ }^{12)}$.

Results are expressed as means \pm standard deviations (SDs). Predicted $\mathrm{VO}_{2}$ max values were analyzed using unpaired t-tests for comparison between smokers and nonsmokers. Baseline levels of oxidative stress markers in plasma and EBC samples were analyzed using unpaired t-tests for comparison between smokers and nonsmokers. Oxidative stress markers in plasma and EBC samples were compared using 2-way analysis of variance with repeated measures. The relationship between cumulative cigarette consumption and levels of oxidative stress markers in plasma and EBC samples were assessed using Pearson's correlation coefficients. p-values of less than 0.05 were considered statistically significant. All statistical analyses were performed using statistics software (IBM SPSS Statistics 21, IBM Japan, Tokyo, Japan).

\section{RESULTS}

There were no significant differences in mean age, height, weight, or body mass index between smokers and nonsmokers (mean age, $27.4 \pm 4.4$ vs. $26.7 \pm 3.1$ years; height, $1.73 \pm 0.06$ vs. $1.73 \pm 0.07 \mathrm{~m}$; weight, $70.2 \pm 8.9$ vs. $66.4 \pm 4.8 \mathrm{~kg}$; body mass index, $23.4 \pm 3.2$ vs. $22.2 \pm$ $1.7 \mathrm{~kg} / \mathrm{m}^{2}$ ). Cumulative cigarette consumption of smokers was $6.8 \pm 4.5$ pack-years. Spirometric data of smokers were within normal limits. There were no significant differences in spirometric parameters between smokers and nonsmokers (percent of predicted forced vital capacity [FVC], 93.0 $\pm 10.8 \%$ vs. $89.5 \pm 5.3 \%$; forced expiratory volume in $1 \mathrm{~s}$ (FEV1.0)/FVC, $84.1 \pm 3.9 \%$ vs. $88.4 \pm 6.9 \%$; percent of predicted FEV1.0, $94.4 \pm 4.8 \%$ vs. $99.3 \pm 7.1 \%$ ). There were no significant differences in predicted $\mathrm{VO}_{2}$ max values in the CPX between smokers and nonsmokers (smokers, 43.5 $\pm 3.2 \mathrm{~mL} / \mathrm{kg} / \mathrm{min}$ vs. nonsmokers, $45.1 \pm 6.5 \mathrm{~mL} / \mathrm{kg} / \mathrm{min}$ ).

Plasma hydroperoxide concentrations in smokers were $307.8 \pm 33.6$ U. Carr at baseline, $312.5 \pm 33.2$ U. Carr immediately after exercise, and $312.4 \pm 52.4 \mathrm{U}$. Carr at $15 \mathrm{~min}$ after exercise. Plasma hydroperoxide concentrations in nonsmokers were $283.8 \pm 42.9$ U. Carr at baseline, 310.6 \pm 47.1 U. Carr immediately after exercise, and $297.8 \pm 37.7$ U. Carr at $15 \mathrm{~min}$ after exercise. No significant interactions between groups were observed at any time point. Additionally, while no main effect of group was observed, a main effect of time was observed $(\mathrm{p}<0.05)$. The $\mathrm{H}_{2} \mathrm{O}_{2}$ concentrations in EBC samples from smokers were $3.2 \pm 1.3 \mu \mathrm{mol} / \mathrm{L}$ at baseline and $1.3 \pm 0.8 \mu \mathrm{mol} / \mathrm{L}$ after exercise, while those for nonsmokers were $2.2 \pm 1.0 \mu \mathrm{mol} / \mathrm{L}$ at baseline and 1.4 $\pm 0.8 \mu \mathrm{mol} / \mathrm{L}$ after exercise. There were no significant differences in baseline EBC $\mathrm{H}_{2} \mathrm{O}_{2}$ concentrations between smokers and nonsmokers. No significant interactions were observed between groups by time. Again, while no main effect of group was observed, a main effect of time was observed $(\mathrm{p}<0.05)$.

There was no significant correlation between cumulative cigarette consumption (pack-years) and levels of oxidative stress markers at baseline (plasma hydroperoxide concentration, $r=-0.050, \mathrm{p}=0.890 ; \mathrm{EBC}_{2} \mathrm{O}_{2}$ concentration, $r=$ $-0.152, \mathrm{p}=0.675)$.

\section{DISCUSSION}

The present study examined plasma and pulmonary oxidative stress in response to moderate-intensity exercise in smokers and nonsmokers. We found that there were no significant interactions between groups in terms of plasma and pulmonary oxidative stress markers following moderateintensity exercise at any time point. In addition, there were no relationships between cumulative cigarette consumption and levels of oxidative stress markers in plasma or EBC samples.

Production of ROS has been reported to be dependent on the intensity ${ }^{15)}$ and duration of exercise ${ }^{16)}$ because ROS generation results from the increase in oxygen consumption observed during exercise. In particular, many reports have found that high-intensity exercise and endurance training induce oxidative damage ${ }^{10,17,18)}$. Exercise-induced oxidative stress is also increased by cigarette smoking. Indeed, multiple studies have found that plasma oxidative stress after strenuous exercise is higher in smokers than in nonsmokers ${ }^{11,13)}$. However, these effects have not been examined following moderate-intensity exercise, which is opti- 
mal for promoting health, improvement of physical fitness, and rehabilitation. The results of this study suggested that cigarette smoking did not increase plasma oxidative stress following moderate-intensity exercise in young cigarette smokers, as evidenced by the fact that no significant interaction in plasma oxidative stress markers was observed between groups at any time point.

Smoking has been reported to increase oxidative stress in the lungs ${ }^{3)}$. Although the $\mathrm{EBC} \mathrm{H}_{2} \mathrm{O}_{2}$ concentrations in nonsmokers were not increased by $30 \mathrm{~s}$ of anaerobic exercise ${ }^{19)}$, the $\mathrm{EBC} \mathrm{H}_{2} \mathrm{O}_{2}$ concentrations in smokers were significantly increased by this exercise ${ }^{12)}$. In our current study, no significant interaction in $\mathrm{EBC} \mathrm{H}_{2} \mathrm{O}_{2}$ concentrations was observed between groups at any time. Thus, these data suggested that cigarette smoking did not increase pulmonary oxidative stress after moderate-intensity exercise.

There were no significant differences between smokers and nonsmokers in terms of plasma hydroperoxide concentrations and $\mathrm{EBC} \mathrm{H}_{2} \mathrm{O}_{2}$ concentrations at baseline, and there were no significant relationships between levels of oxidative stress markers at baseline and cumulative cigarette consumption in the present study. Nowak et al. ${ }^{3)}$ reported that smokers with a long smoking history have high EBC $\mathrm{H}_{2} \mathrm{O}_{2}$ concentrations and that there is a positive correlation between $\mathrm{H}_{2} \mathrm{O}_{2}$ levels in the $\mathrm{EBC}$ and cumulative cigarette consumption. Cumulative cigarette consumption may be related to pulmonary oxidative stress. However, we may have observed no relationship between cumulative cigarette consumption and pulmonary oxidative stress in this study because the cumulative cigarette consumption of the participants in our study was much lower than that in some previous studies $\left(17.8^{3)}\right.$ and 22.0 pack-years ${ }^{20)}$ ).

A limitation of this study was that the young cigarette smokers enrolled in the study had relatively low cumulative cigarette consumptions. It was reported that the amount of systemic or airway inflammation in elderly smokers who had long smoking histories was larger than in young smokers. If elderly smokers stopped smoking, systemic and airway inflammation persists for long periods ${ }^{21)}$. Therefore, further studies of elderly smokers who undergo exercise therapy under the guidance of physical therapists are needed to address changes in oxidative stress markers in response to moderate-intensity exercise.

In conclusion, our data demonstrated that moderate-intensity exercise may not increase the risk of systemic and pulmonary oxidative damage in young cigarette smokers.

\section{REFERENCES}

1) Pryor WA, Stone K: Oxidants in cigarette smoke. Radicals, hydrogen peroxide, peroxynitrate, and peroxynitrite. Ann N Y Acad Sci, 1993, 686: 12-27. [Medline] [CrossRef]

2) Morrow JD, Frei B, Longmire AW, et al.: Increase in circulating product of lipid peroxidation (F2-isoprostanes) in smokers. Smoking as a cause of oxidative damage. N Engl J Med, 1995, 332: 1198-1203. [Medline] [CrossRef]

3) Nowak D, Kalucka S, Bialasiewicz P, et al.: Exhalation of $\mathrm{H}_{2} \mathrm{O}_{2}$ and thiobarbituric acid reactive substances (TBARs) by healthy subjects. Free Radic Biol Med, 2001, 30: 178-186. [Medline] [CrossRef]

4) Ambrose JA, Barua RS: The pathophysiology of cigarette smoking and cardiovascular disease: an update. J Am Coll Cardiol, 2004, 43: 1731-1737. [Medline] [CrossRef]

5) Hecht SS: Tobacco smoke carcinogens and lung cancer. J Natl Cancer Inst, 1999, 91: 1194-1210. [Medline] [CrossRef]

6) MacNee W: Oxidants/antioxidants and COPD. Chest, 2000, 117: 303S317S. [Medline] [CrossRef]

7) Vollaard NB, Shearman JP, Cooper CE: Exercise-induced oxidative stress: myths, realities and physiological relevance. Sports Med, 2005, 35: 10451062. [Medline] [CrossRef]

8) Finaud J, Lac G, Filaire E: Oxidative stress: relationship with exercise and training. Sports Med, 2006, 36: 327-358. [Medline] [CrossRef]

9) Cooper CE, Vollaard NB, Choueiri T, et al.: Exercise, free radicals and oxidative stress. Biochem Soc Trans, 2002, 30: 280-285. [Medline] [CrossRef]

10) Fisher-Wellman K, Bloomer RJ: Acute exercise and oxidative stress: a 30 year history. Dyn Med, 2009, 8: 1-25. [Medline] [CrossRef]

11) Bloomer RJ, Creasy AK, Smith WA: Physical work-induced oxidative stress is exacerbated in young cigarette smokers. Nicotine Tob Res, 2007, 9: 205-211. [Medline] [CrossRef]

12) Taito S, Sekikawa K, Domen S, et al.: Pulmonary oxidative stress is induced by maximal exercise in young cigarette smokers. Nicotine Tob Res, 2012, 14: 243-247. [Medline] [CrossRef]

13) Taito S, Sekikawa K, Oura K, et al.: Plasma oxidative stress is induced by single-sprint anaerobic exercise in young cigarette smokers. Clin Physiol Funct Imaging, 2013, 33: 241-244. [Medline] [CrossRef]

14) Garber CE, Blissmer B, Deschenes MR, et al.: American College of Sports Medicine position stand. Quantity and quality of exercise for developing and maintaining cardiorespiratory, musculoskeletal, and neuromotor fitness in apparently healthy adults. Med Sci Sports Exerc, 2011, 43: 13341359. [Medline] [CrossRef]

15) Lovlin R, Cottle W, Pyke I, et al.: Are indices of free radical damage related to exercise intensity. Eur J Appl Physiol Occup Physiol, 1987, 56: 313-316. [Medline] [CrossRef]

16) Bloomer RJ, Davis PG, Consitt LA, et al.: Plasma protein carbonyl response to increasing exercise duration in aerobically trained men and women. Int J Sports Med, 2007, 28: 21-25. [Medline] [CrossRef]

17) Fogarty MC, Hughes CM, Burke G, et al.: Exercise-induced lipid peroxidation: implications for deoxyribonucleic acid damage and systemic free radical generation. Environ Mol Mutagen, 2011, 52: 35-42. [Medline] [CrossRef]

18) Child RB, Wilkinson DM, Fallowfield JL, et al.: Elevated serum antioxidant capacity and plasma malondialdehyde concentration in response to a simulated half-marathon run. Med Sci Sports Exerc, 1998, 30: 1603-1607. [Medline] [CrossRef]

19) Domen S, Taito S, Konishi K, et al.: Pulmonary oxidative stress is not increased by short-period high intensity exercise in healthy young subjects. Rigakuryoho Kagaku, 2011, 26: 287-290 (in Japanese). [CrossRef]

20) Cantin AM, North SL, Hubbard RC, et al.: Normal alveolar epithelial lining fluid contains high levels of glutathione. J Appl Physiol, 1987, 63: 152-157. [Medline]

21) Tracy RP, Psaty BM, Macy E, et al.: Lifetime smoking exposure affects the association of $\mathrm{C}$-reactive protein with cardiovascular disease risk factors and subclinical disease in healthy elderly subjects. Arterioscler Thromb Vasc Biol, 1997, 17: 2167-2176. [Medline] [CrossRef] 